\title{
EQUILIBRIUM DIALYSIS STUDIES OF THE BINDING OF THYROXINE BY HUMAN SERUM ALBUMIN *
}

\author{
By KENNETH STERLING, PHILIP ROSEN † AND MILTON TABACHNICK $\ddagger$ \\ (From the Department of Internal Medicine, New York State Psychiatric Institute, and the \\ Department of Psychiatry, Columbia University College of Physicians and \\ Surgeons, New York, N. Y.)
}

(Submitted for publication July 20, 1961 ; accepted December 28, 1961)

In previous work from this laboratory (1) studies on equilibrium dialysis were carried out to determine the binding constants for the interaction of human serum albumin with thyroxine and its analogs. The classical technique of equilibrium dialysis as described by Scatchard and others (2-6) was employed.

At present it seems clear that thyroxine in human serum migrates to at least three different sites during electrophoresis at $\mathrm{pH} 8.6(7-10)$. The three sites most frequently reported have been the thyroxine-binding $\alpha$-globulin (TBG), albumin, and the "prealbumin" region. The thyroxinebinding $\alpha$-globulin has generally been considered of major physiological importance, the others being regarded as secondary carriers. Albumin is the only one of the thyroxine carriers of serum readily available in pure form and with a known molecular weight.

The findings of the previous work (1) appeared compatible with the hypothesis that the anionic phenolate groups of thyroxine and triiodothyronine interact with free cationic groups on the protein molecule. In the present report the observations have been extended to studies with variations in temperature and $\mathrm{pH}$, as well as to experiments with mercaptalbumin, isooctane-extracted albumin, and acetylated albumin preparations. The present findings provide further support for the concept of an interaction of the anionic phenolate groups of thyroxine and four cationic groups on the protein molecule. More-

\footnotetext{
* Work done under U. S. Atomic Energy Commission contract AT (30-1)-2361, and supported by grants from the American Cancer Society and the National Institutes of Health (A-2770 Endo).

$\dagger$ Present address: Department of Chemistry, New York University, Washington Square 3, New York, N. Y.

$\ddagger$ Present address: Department of Biochemistry, New York Medical College, New York, N. Y.
}

over, the evidence suggests that the four primary binding sites may be $\epsilon$-amino groups of lysine residues. The binding constants for the albumin-thyroxine interaction have been employed to calculate the theoretical free thyroxine concentration in human serum.

\section{MATERIALS AND METHODS}

Most of the albumin used was supplied by the American Red Cross; these amorphous albumin solutions had been stabilized by the addition of $0.02 \mathrm{M}$ sodium caprylate and $0.02 \mathrm{M}$ sodium acetyltryptophanate. Consequently, all Red Cross albumin preparations were dialyzed against several changes of isotonic saline solution and then deionized by passage through Amberlite MB-1 resin, according to the method of Dintzis (11). Such treatment has produced isoionic albumin, freed of added stabilizers (11). Bound fatty acids (12) may be removed to an extent of approximately 1 mole of fatty acid remaining per mole of albumin $(6,13)$ after passage through the mixed-bed resin.

Upon electrophoretic analysis the deionized amorphous albumin preparations were found to be 98 per cent pure. Addition of minute tracer amounts of $\mathrm{I}^{131}$-labeled thyroxine, followed by electrophoresis at $\mathrm{pH} 8.6$ in Tris-maleate buffer, demonstrated that the albumin solutions were free of detectable thyroxine-binding $\alpha$-globulin or prealbumin.

Crystalline human mercaptalbumin, which had been passed through the mixed-bed resin, Amberlite MB-1, was supplied as a dry powder by the Protein Foundation, Jamaica Plain, Mass., though the courtesy of Drs. J. L. Oncley and R. B. Pennell.

For studies of albumin free of bound fatty acid, the amorphous Red Cross albumin, which had been deionized, was subjected to isooctane extraction by the method of Goodman (13).

For studies of the mechanism of binding, acetylated human serum albumin preparations were made. Acetylation was carried out after the procedure of FraenkelConrat, Bean and Lineweaver (14). The acetic anhydride was added gradually over a 60 -minute period to a 5 per cent protein solution in half-saturated sodium acetate, the reaction mixture being held in an ice bath. The acetylated protein was precipitated at $\mathrm{pH} 4.0$ and collected by centrifugation (15), then dialyzed against three 
successive daily changes of deionized water at $4^{\circ} \mathrm{C}$. The degree of acetylation was controlled by the amount of acetic anhydride added to each protein solution. The extent of acetylation was subsequently measured by the ninhydrin reaction.

All protein solutions were stored frozen. Repeated freezing and thawing had no detectable effect on the thyroxine-albumin interaction. The protein concentrations were measured by the biuret reaction as described by Gornall, Bardawill and David (16), employing as standards protein solutions prepared from weighed amorphous proteins, or checked by micro-Kjeldahl determinations, or both. Protein concentrations were also determined spectrophotometrically at $280 \mathrm{~m} \mu$, with an extinction coefficient of 5.3 for a 1 per cent solution of human serum albumin (17).

$\mathrm{I}^{131}$-labeled L-thyroxine was obtained from E. R. Squibb and Co. or from Abbott Laboratories. Nonradioactive L-thyroxine was purchased from Mann Research Co., New York, N. Y. The radioactive tracer was added to solutions of carrier thyroxine which had been diluted from a stock solution prepared by dissolving a weighed amount of the material. The tracer, in the presence of adequate amounts of carrier, was stable at $4^{\circ} \mathrm{C}$ for 3 weeks or more upon chromatographic analysis, whereas in dilute solution the carrier-free tracer underwent decomposition.

Each radioactive shipment was checked for purity by paper chromatography on duplicate $56-\mathrm{cm}$ strips of Whatman $3 \mathrm{MM}$ paper, previously prepared with application of nonradioactive carriers at the origin. Descending paper chromatography was carried out with a butanol: dioxane: ammonia system $(4: 1: 5$, vol/vol) for 16 hours; the dried paper strips were then scanned with a NuclearChicago Actigraph IIB, model C-100 B. After scanning, the position of carriers was obtained by color development upon spraying with palladium chloride for iodide and 4-aminoantipyrene for thyroxine and analogs (18). In the studies illustrated, no radioactive peaks other than thyroxine were observed, except for small traces of inorganic iodide (less than 2 per cent). In a few instances shipments with iodide contamination in excess of 2 per cent were employed, with appropriate corrections, based on the observation that binding of iodide by albumin was small in comparison with thyroxine binding. Paper chromatography repeated after dialysis revealed no alteration of thyroxine under the experimental conditions.

The following buffers were employed for dialysis: potassium phosphate, $\mathrm{pH} 7.0$ and $\mathrm{pH} 7.4,0.15$ ionic strength; Tris-sodium chloride, $\mathrm{pH} 7.4$ and $\mathrm{pH} 8.6(0.05$ $\mathrm{M}$ Tris- $0.1 \mathrm{M} \mathrm{NaCl}$ ) ; sodium borate, $\mathrm{pH} 8.6,0.15$ ionic strength; sodium glycinate, $\mathrm{pH} 9.8,0.2 \mathrm{M}$ glycinate; potassium phosphate, $\mathrm{pH} 10.5,10.9$, and 11.2 with 0.15 ionic strength.

The phosphate buffers were isotonic (ionic strength, $0.15)$ and the Tris-sodium chloride buffers were very close to this ionic strength. The sodium glycinate buffer was somewhat hypertonic.

Equilibrium dialysis procedure. Dialysis bags were made from Visking sausage casing (30/32 inch). The dialysis membranes were specially cleaned by soaking them first in $0.1 \mathrm{M}$ nitric acid for 16 to 24 hours, and then for 2 to 3 days in $0.01 \mathrm{M}$ nitric acid, followed by storage in deionized water at $4^{\circ} \mathrm{C}$ (1). Prior to use the bags were washed repeatedly with deionized or glass-distilled water and dried for 6 to 16 hours at room temperature. To insure optimal mixing, a marble was placed within the bag before addition of protein solution. Five $\mathrm{ml}$ of protein solution with buffer was added inside the bag and $5 \mathrm{ml}$ of isotonic buffer solution was added to the outside. Dialysis was carried out in $50-\mathrm{ml}$ plastic centrifuge tubes $(28 \times 102 \mathrm{~mm})$; adsorption of thyroxine in dilute solution by glassware was obviated by the use of plastic (cellulose nitrate) tubes. The tubes were placed in a water-bath shaker with temperature at $38^{\circ}$ or $30^{\circ} \mathrm{C}$ and in a few instances at $5^{\circ} \mathrm{C}$.

Recovery of $\mathrm{I}^{131}$-thyroxine ranged from 95 to 105 per cent, even in control runs in the absence of protein, indicating no significant binding by the dialysis bags or by the walls of the plastic tubes.

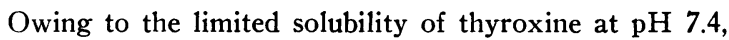
it was necessary to work with low thyroxine concentrations, and it was not feasible to vary the thyroxine concentrations more than tenfold. Higher concentrations resulted in visible precipitation. In most of the studies the concentration of thyroxine ranged from $2.6 \times 10^{-8} \mathrm{M}$ to $2.6 \times 10^{-5} \mathrm{M}$, expressed as the final concentration in the 5-ml protein solution. As shown below, this tenfold variation of thyroxine concentration proved adequate for studies of the primary binding sites. With the increased solubility of thyroxine in more alkaline solutions, a greater range of concentrations was possible. At $\mathrm{pH} 9.8$ the concentration of thyroxine was varied 90 -fold without difficulty. The albumin concentration usually employed within the dialysis bag was $0.1 \mathrm{~g}$ per $100 \mathrm{ml}(1.45 \times$ $\left.10^{-5} \mathrm{M}\right)$. The use of higher concentrations of albumin, such as $0.2 \mathrm{~g}$ per $100 \mathrm{ml}$, restricted the possible ratios of thyroxine to protein because of the limited thyroxine solubility. Variations in protein concentration had no appreciable effect upon the results obtained. Therefore the more dilute albumin solutions were used in the majority of the experiments, since they permitted a larger number of experimental points.

EDTA at a final concentration of $3.4 \times 10^{-4} \mathrm{M}$ was also added (1). Presumably the EDTA prevents thyroxine in dilute solution on the nonprotein side of the bag from forming complexes with minute traces of metal ions (19, 20). When dialysis studies were run without EDTA, proper equilibrium was not obtained in tubes to which the thyroxine was added outside the bag.

To achieve equilibrium, a period of 4 hours was adequate at $38^{\circ} \mathrm{C}$, but overnight (16 hours) shaking in the water bath was usually employed and was always used at temperatures below $38^{\circ}$. Appreciable bacterial growth was not observed. In control tubes with no protein inside the bag, radioactivity was essentially the same in both compartments after 4 or 16 hours of shaking at $38^{\circ} \mathrm{C}$. With the dilute protein solutions employed, no significant volume change was observed, although similar 


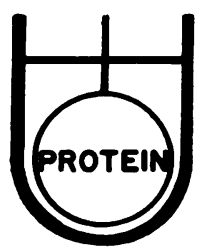

Fraction Bound $=\frac{\mathrm{cpm} \text { inside }-\mathrm{cpm} \text { outside }}{\text { total } \mathrm{cpm}}$

$\nabla=\frac{\text { moles } T_{4} \text { bound }}{\text { mole albumin }}$

$A=$ concentration (activity) of free $\mathrm{T}_{4}$

$$
\begin{aligned}
& n=\frac{\text { maximum moles } T_{4} \text { bound }}{\text { mole albumin }} \\
& k=\text { opparent association constant }
\end{aligned}
$$

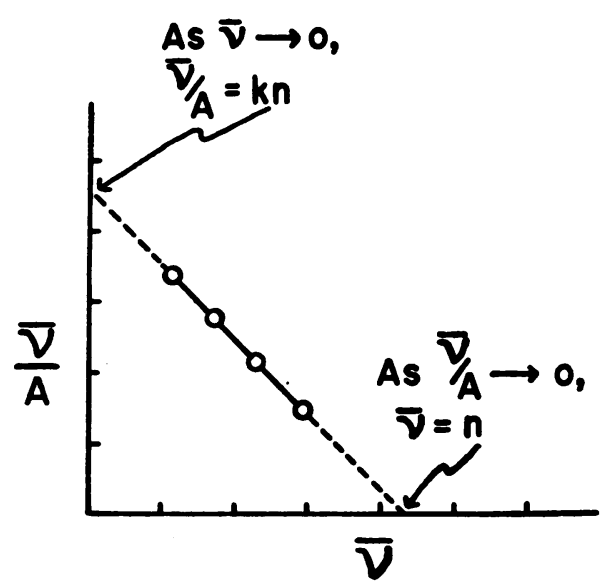

$\bar{V} / \mathbf{A}=k n-k \bar{v}$

Fig. 1. Equilibrium dialysis study of thyroxine binding by human SERUm albumin (SCATChard plot).

studies with undiluted serum, described separately (21), resulted in a volume change of $0.5 \mathrm{ml}$ owing to osmosis under the conditions described.

In all studies a series of graded increments of thyroxine (carrier thyroxine mixed with tracer) was employed with the same protein solution. No change in $\mathrm{pH}$ occurred during dialysis, as measured with the Beckman model G $\mathrm{pH}$ meter. After equilibration, aliquots were taken from both the inside and outside of the dialysis bag and counted in a Packard Auto-Gamma well-type scintillation counter. The fraction of thyroxine bound was obtained from the quotient: (cpm inside - cpm outside)/total cpm.

The Scatchard approach $(2-4)$ was used to obtain the binding constants for the interaction of thyroxine and albumin. Figure 1 illustrates the Scatchard equation and defines the symbols. From the protein concentration employed, the thyroxine concentration added, and the "fraction bound," the value for $\bar{\nu}$ was computed for each of the tubes of the study. The value for $A$, the free thyroxine concentration, was obtained from counts per minute outside by employing the known thyroxine concentration added. The values of $\bar{\nu} / \mathrm{A}$ plotted against $\bar{\nu}$ give a straight line when all the binding sites are equivalent and independent (2-6). As illustrated in the idealized Scatchard plot in Figure 1, the dotted line extrapolations to the axes are employed to obtain binding constants. The intercept on the $\bar{\nu}$ axis is $n$, as $\bar{\nu} / \mathrm{A}$ approaches zero as a limit, and the intercept on the $\bar{\nu} / \mathrm{A}$ axis is $k n$ as $\bar{\nu}$ approaches zero as a limit. The quotient $k n / n$ gives $k$, the apparent association constant, an expression that is the reciprocal of the dissociation constant. The Scatchard equation may be derived from the mass law (2-5). When binding takes place at more than one set of sites with different association constants, deviations from linearity are observed. Curvature may also occur in the binding of di- or trivalent ions by proteins, since the addition of successive ions to each of a class of essentially identical sites may produce differences in apparent association constants because of appreciable alteration of the net charge of the protein-ion complex (2-6).

The binding of each concentration of thyroxine was always determined by setting up tubes in duplicate. In one tube the labeled compound was added to the protein solution inside the dialysis bag; in the other tube it was added to the protein-free solution outside. If both of the duplicate tubes reach equilibrium there should be the same fraction of $\mathrm{I}^{131}$-thyroxine bound. Therefore, $\bar{\nu}$ and $\mathrm{A}$ should be the same in both cases where the interaction is a true equilibrium. Figure 2 shows that reasonable correspondence between duplicates is actually obtained, and that a linear relationship exists between $\bar{\nu} / \mathrm{A}$ and $\bar{\nu}$ for the binding of thyroxine by crystalline human mercaptalbumin at $\mathrm{pH} 8.6$ and $30^{\circ} \mathrm{C}$. This experiment was typical of all acceptable studies under the varying experimental conditions; reasonable equilibration was indicated by the close correspondence of "inside" and "outside" points. In the presence of EDTA the values of paired tubes usually agreed within 5 per cent.

Inspection of Figure 2 reveals that all the triangles are above the line and all the circles below it. This was typical of all studies except that occasionally some of the inside and outside points corresponded so closely as to be 


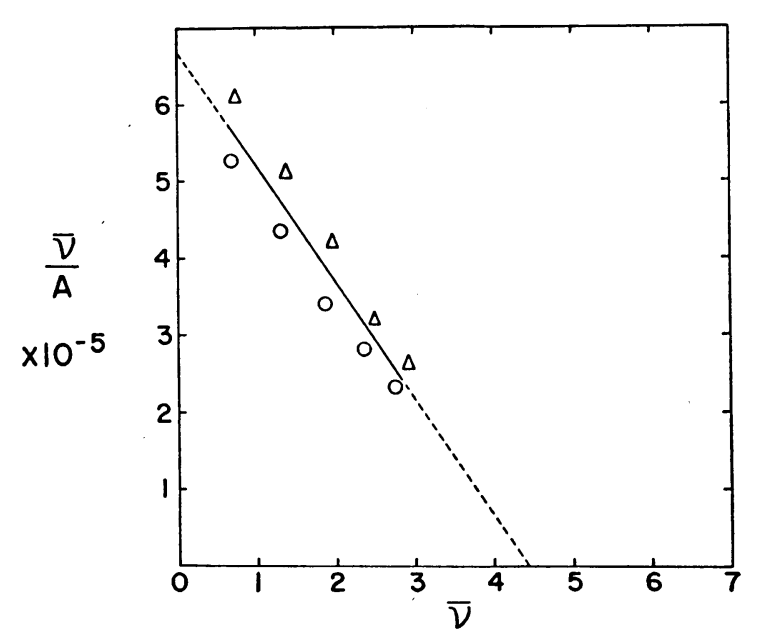

Fig. 2. EQUILIBRIUM DIALYSIS STUDY OF L-THYROXINE BINDING BY CRYSTALLINE HUMAN MERCAPTALBUMIN. $30^{\circ} \mathrm{C}$, pH 8.6, $0.05 \mathrm{M}$ Tris- $0.1 \mathrm{M} \mathrm{NaCl} ; \Delta=$ thyroxine added to protein solution inside bag; $\mathrm{O}=$ thyroxine added to nonprotein solution outside bag.

indistinguishable. The line was determined by points representing the mean values of the inside and outside points. Figures subsequent to Figure 2 illustrate the mean values.

In the absence of EDTA the points obtained from tubes to which thyroxine was added to the nonprotein side of the bag were quite far below a line drawn through the points obtained from inside additions, as illustrated previously (1). Therefore, EDTA was necessary for equilibration only where thyroxine was added outside the bag but was employed in all studies nevertheless for uniformity of conditions.

\section{RESULTS AND COMMENTS}

1. The binding of thyroxine by crystalline human mercaptalbumin. The findings in a typical equilibrium dialysis study are illustrated in Figure 2 . The binding data were analyzed by means of the Scatchard equation as described in Figure 1 and Methods. Satisfactory correspondence between the duplicates (triangles and circles in the figure) is evident upon inspection; such satisfactory agreement was obtained only in the presence of EDTA. A linear relationship exists between $\bar{\nu} / \mathrm{A}$ and $\bar{\nu}$. The extrapolations to the $\bar{\nu} / \mathrm{A}$ axis, $k n$, and the $\bar{v}$ axis, $n$, are shown by the dotted lines. The intercepts gave a value of 4.43 for $n$; the $k n$ value obtained was 665,000 . The quotient $665,000 /$ 4.43 equals 150,000 , the value for $k$, the association constant. An association constant of this magnitude represents a somewhat firmer binding than that of many small molecules known to be bound to albumin, such as methyl orange (5) and tryptophan (6), but much less firm binding than the interaction of human serum albumin with the free fatty acids of serum (12).

The results of albumin-thyroxine interactions at $\mathrm{pH} 8.6$ are quite similar to the findings at $\mathrm{pH} 7.4$, as shown below; however, this is not the case when the small molecule is triiodothyronine, as is subsequently discussed. At $\mathrm{pH} 8.6$ the same results were obtained with Tris-sodium chloride and with sodium borate buffers.

2. The binding of thyroxine by human serum albumin at $p H 7.4$ and $38^{\circ} \mathrm{C}$. The interaction of L-thyroxine with amorphous preparations of serum albumin was studied at $\mathrm{pH} 7.4$ in two buffer systems: 1) potassium phosphate buffer, ionic strength 0.15 ; and 2$)$ Tris-sodium chloride $(0.05$ $\mathrm{M}$ Tris- $0.1 \mathrm{M} \mathrm{NaCl}$ ). The two buffer systems gave similar results at the same $\mathrm{pH}$. A typical experiment with dialyzed and deionized amorphous albumin is illustrated in Figure 3 . The value for $k n$ is $420,000, n$ is 4.2 , and $k$ is therefore 100,000 . It will be observed that the two points near the ordinate are not close to the line. Such scattering, above or below the line, was frequent in most experiments for the points representing the smallest amounts of thyroxine. It is evident on mathematical grounds that less accurate

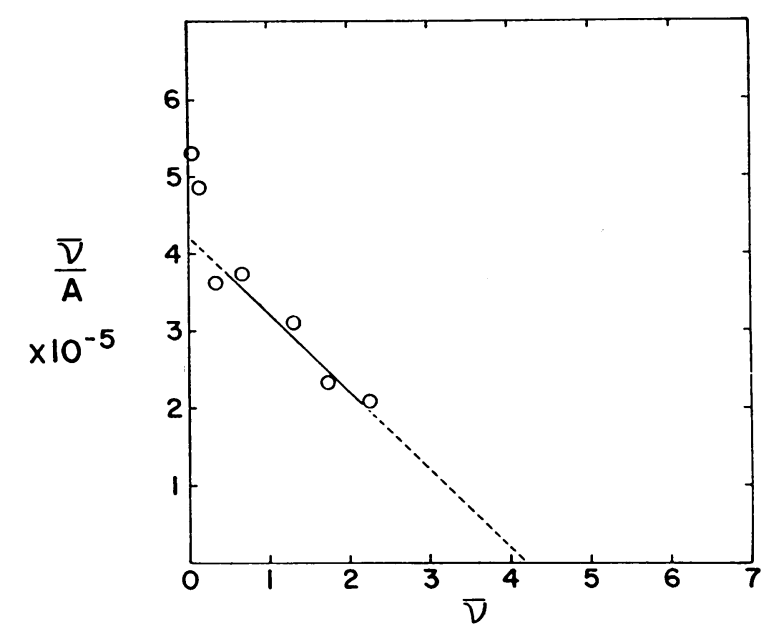

Fig. 3. EQUilibrium dialysis StUdy OF L-Thyroxine BINDING BY HUMAN SERUM ALbUMiN. $38^{\circ} \mathrm{C}, \mathrm{pH} 7.4$, phosphate buffer, 0.15 ionic strength. The points represent the mean values of "inside" and "outside" additions for each amount of thyroxine. 
data can be obtained where the "fraction bound" is high (in excess of 90 per cent), since the numerator represents the difference between a large and a small number. The most accurate data were invariably obtained for points in the intermediate portion of the curve. At $\mathrm{pH} 7.4$ the limited solubility of thyroxine made it impossible to obtain points for higher concentrations of thyroxine than are illustrated. Inspection of the dotted line extrapolations to the axes reveal that the extrapolation to the abscissa is longer than that to the ordinate. Consequently the values for $n$ may be subject to an error of about 10 per cent and may be somewhat less accurate than the values for $k n$, owing to the shorter extrapolation required. In ten equilibrium dialysis experiments with amorphous albumin in phosphate buffer at $\mathrm{pH} 7.4$, the mean value for $n$ was $4.0 \pm 0.3$ (standard deviation), and the mean value for $k$ was $107,000 \pm$ 12,000 . In eight experiments at $\mathrm{pH} 8.6$ with Tris-sodium chloride buffer, the mean value for $n$ was $4.1 \pm 0.2$ and the mean value for $k$ was $110,000 \pm 15,000$ (cf Table I).

It is evident that the results at $\mathrm{pH} 7.4$ and 8.6 do not differ appreciably. The results selected for illustration showed the least scatter of experimental points and are considered the most accurate. Since the number of binding sites should be an integer, it may be inferred from the data that the albumin molecule has a primary class of four thyroxine binding sites with an apparent association constant of approximately 100,000 . No immediate explanation is apparent for the difference in association constants of 150,000 for crystalline human mercaptalbumin and 100,000 for amorphous human albumin, which differ in that each of the mercaptalbumin molecules possesses a free sulfhydryl group. The amorphous albumin preparations from the American Red Cross may be presumed to consist partly of mercaptalbumin, although the proportion was not determined in the individual lots. These amorphous preparations had been stabilized prior to acquisition by the addition of $0.02 \mathrm{M}$ sodium caprylate (octanoate) and $0.02 \mathrm{M}$ sodium acetyltryptophanate. This concentration corresponds to 5.5 molecules of caprylate and acetyltryptophanate per albumin molecule in the original solution. The binding of caprylate to albumin is relatively weak (22), and much of it was probably removed by the dialysis against isotonic saline prior to use. Moreover, passage through the mixed-bed resin removes these preservatives as well as much of the bound fatty acid (11-13). Since both the crystalline mercaptalbumin and the amorphous albumin preparations had been passed through Amberlite MB-1, one cannot assume that differences in the amount of fatty acids bound by the two proteins could explain the discrepancy between the association constants. However, in the absence of data on bound fatty acids, this possibility remains to be excluded (cf 6 , below).

3. The effect of temperature. The results at $30^{\circ}$ and $38^{\circ} \mathrm{C}$ did not differ appreciably; as illustrated in Figure 4, however, low temperature $\left(5^{\circ} \mathrm{C}\right)$ resulted in appreciably tighter binding. The free energy of binding $\left(-\Delta \mathrm{F}^{\circ}\right)$, computed for $38^{\circ} \mathrm{C}$, approximated 7,200 calories per mole, a value somewhat greater than that for the association of bovine serum albumin with methyl orange (5).

4. Second binding site on albumin. Lein (23, 24) has described two classes of binding sites for the interaction of L-thyroxine with bovine serum albumin at $\mathrm{pH} 9.75$ in glycinate buffer. Since the solubility of thyroxine is increased at an alkaline $\mathrm{pH}$, it was possible to extend the experimental points by using more concentrated thyroxine solutions. A study at $\mathrm{pH} 9.8$ in $0.2 \mathrm{M}$ glycinate buffer is illustrated in Figure 5, in which the flatter segment of the curve with greater amounts of thyroxine is clearly evident. The data at $\mathrm{pH} 9.8$ are

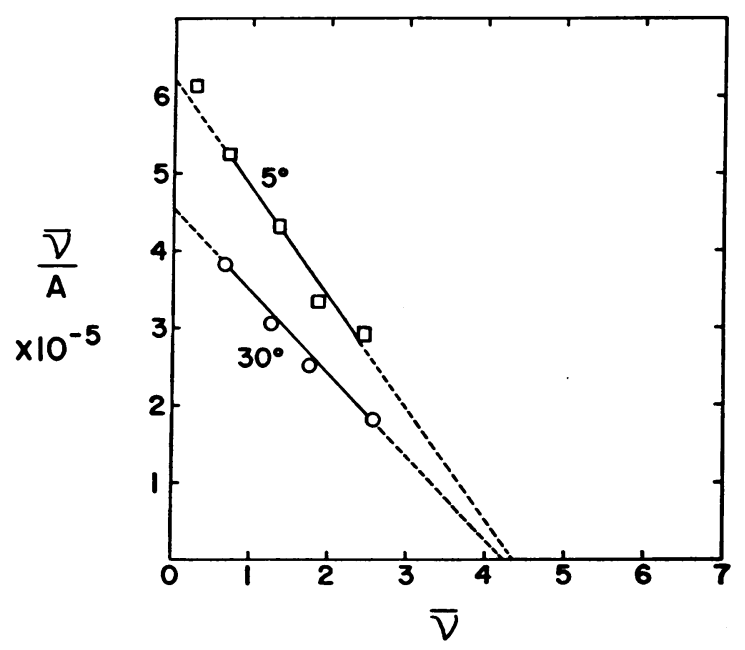

Fig. 4. EFFECT OF TEMPERATURE UPON THE BINDING OF THYROXINE by humaN SERUM ALbUMin. pH 8.6, $0.05 \mathrm{M}$ Tris-0.1 M NaCl. 


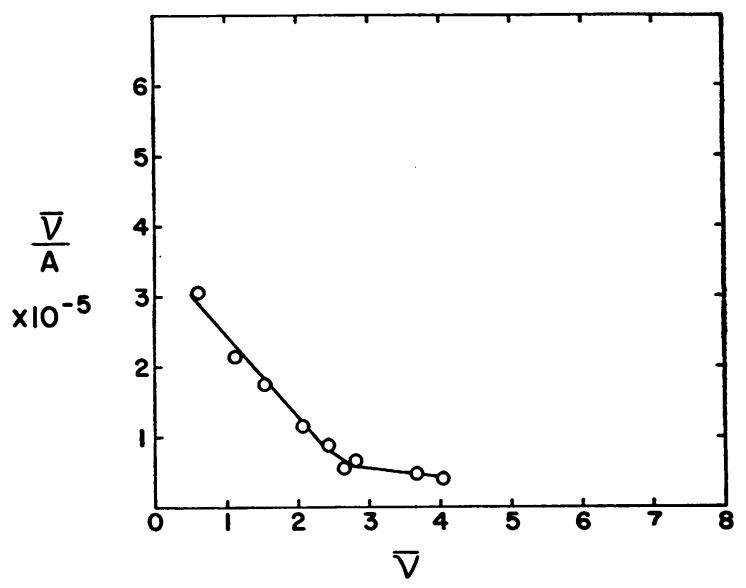

Fig. 5. Second binding Site on the albumin molecule. $30^{\circ} \mathrm{C}, \mathrm{pH}$ 9.8, $0.2 \mathrm{M}$ glycinate buffer.

best described by assuming the existence of two binding sites: $n_{1}=3, k_{1}=143,000 ; n_{2}=$ approximately $20, k_{2}=$ approximately 1,000 . The values for $n_{2}$ and $k_{2}$ represent estimates based upon extrapolations of the flat segment. Theoretical curves constructed with these constants resulted in the closest approximation to the experimental points. Owing to the extremely low concentration of free thyroxine in serum, only the first binding site has physiological importance (cf Discussion).

5. The effect of $p H$. A series of amorphous albumin experiments with varying $\mathrm{pH}$ is presented in Table I. It should be pointed out that at $\mathrm{pH}$ 7.0 the limitation of thyroxine solubility permitted only a few satisfactorily equilibrated points at the lowest values for $\bar{\nu}$; therefore, lines could be drawn with reasonable certainty in only two of four experiments attempted. The results in Table I represent the single most satisfactory experiment of the four, and these values should be regarded as the best approximations obtainable at
$\mathrm{pH}$ 7.0. The appreciable diminution in binding at $\mathrm{pH} 10.9$ is evident. At $\mathrm{pH} 11.2$ with phosphate buffer, the data yielded a low, essentially horizontal curve indicative of pronounced reduction in binding. As discussed below, the reduction in binding with strongly alkaline $\mathrm{pH}$ is compatible with removal of protons from free $-\mathrm{NH}_{3}{ }^{+}$groups on the protein.

6. Isooctane-extracted albumin. Goodman (12) has reported that serum albumin has a primary class of two binding sites for fatty acids, with an association constant of $6 \times 10^{7}$ for palmitate. To investigate the possibility that fatty acids might interfere with the binding of thyroxine, studies were carried out with deionized amorphous albumin preparations which had been subjected to isooctane extraction to free them of bound fatty acids.

The equilibrium dialysis study in Figure 6 revealed no diminution in the number of primary binding sites $(n=4.2)$ and an increased association constant $(k=148,000)$. Similar findings were obtained at $\mathrm{pH} 7.4$. The mean values of four studies with isooctane-extracted albumin were $n=4.2$ and $k=163,000$. The reason for the firmer binding is not evident; possibly, removal of the long-chain fatty acid may free a nonpolar part of the protein molecule important in the interaction. Addition of 2 moles of palmitate per mole of protein to an isooctane-extracted albumin preparation resulted in a curve indistinguishable from the original, as shown (Figure 6).

7. Nature of the principal binding sites of albumin. Since Klotz and Walker (25) presented evidence in support of the interaction of the anionic dye, methyl orange, and the $\epsilon$-amino groups of lysine residues of serum albumin, it seemed reasonable to suppose that these groups might also be involved in the binding of the anionic molecule,

TABLE I

Effect of pH on the binding of L-thyroxine by human serum albumin*

\begin{tabular}{|c|c|c|c|c|c|c|c|c|}
\hline $\mathrm{pH}$ & Buffer & $\begin{array}{c}\text { No. } \\
\text { of } \\
\text { expts. }\end{array}$ & $k_{1} n_{1}$ & $n_{1}$ & $k_{1}$ & $k_{2 n}$ & $n_{2}$ & $k_{2}$ \\
\hline $\begin{array}{r}7.0 \\
7.4 \\
8.6 \\
9.8 \\
9.8 \\
10.9\end{array}$ & $\begin{array}{l}\text { Phosphate } \\
\text { Phosphate } \\
\text { Tris-NaCl } \\
\text { Glycinate } \\
\text { Glycinate } \\
\text { Phosphate }\end{array}$ & $\begin{array}{r}1 \\
10 \\
8 \\
1 \\
7 \\
1\end{array}$ & $\begin{array}{l}370,000 \\
428,000 \\
450,000 \\
430,000 \\
420,000 \\
150,000\end{array}$ & $\begin{array}{l}3.5 \\
4.0 \pm 0.3 \\
4.1 \pm 0.2 \\
3.0 \\
3.3 \pm 0.4 \\
2.0\end{array}$ & $\begin{array}{r}106,000 \\
107,000 \pm 12,000 \\
110,000 \pm 15,000 \\
143,000 \\
127,000 \pm 42,000 \\
75,000\end{array}$ & 20,000 & ca. 20 & ca. 1,000 \\
\hline
\end{tabular}

* Mean values and standard deviations from the mean. For glycinate at $\mathrm{pH} 9.8$, the single most accurate experiment is given in addition. 


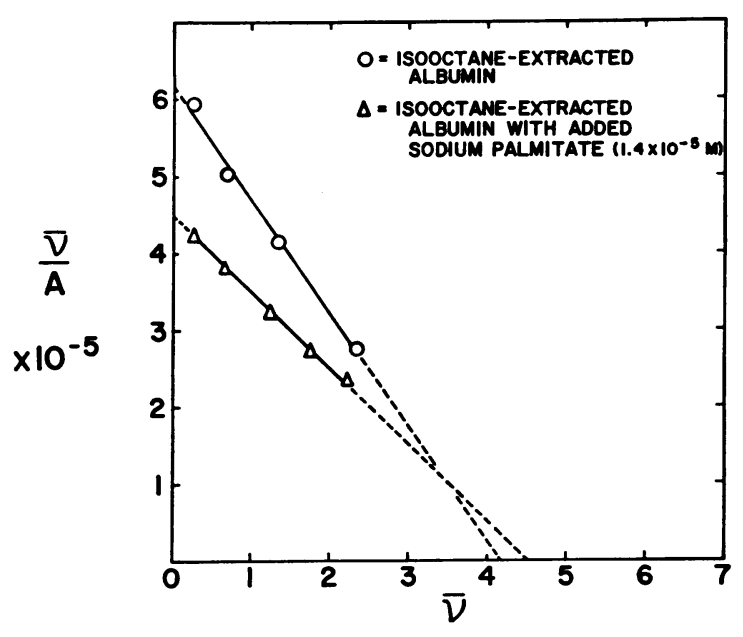

Fig. 6. EFFect of Palmitate on the binding of L-THYROXINE BY ISOOCTANE-EXTRACTED HUMAN SERUM albumin. $30^{\circ} \mathrm{C}, \mathrm{pH} 8.6,0.05 \mathrm{M}$ Tris- $0.1 \mathrm{M} \mathrm{NaCl}$.

thyroxine. A means of testing this hypothesis was provided by studies in which the free amino groups of the protein were blocked by acetylation (14). As illustrated in Figure 7, acetylation of 11 per cent of the lysyl $\epsilon$-amino groups resulted in reduction of $n$ from 4 to 3 , and reduction of the association constant by one-third (from 100,000 to 70,000$)$. Heavier acetylation, which produced blocking of 45 to 75 per cent of the protein amino groups, resulted in more pronounced reduction of binding.

The behavior as a function of variation of $\mathrm{pH}$ is consistent with an interaction of free $-\mathrm{NH}_{3}{ }^{+}$ groups and the small anionic molecule, thyroxine. Thus, at very strongly alkaline reaction $(\mathrm{pH} 10.9$ and 11.2) in the presence of isotonic phosphate buffer, the binding of L-thyroxine is markedly reduced, presumably because most of the $-\mathrm{NH}_{3}{ }^{+}$ groups have lost a proton to become $-\mathrm{NH}_{2}$ groups.

As previously reported (1), the free cationic groups on the protein molecule are believed to interact with the anionic phenolate groups of thyroxine and triiodothyronine. At $\mathrm{pH} 7.4$ triiodothyronine was bound only one-tenth as tightly as L-thyroxine and D-thyroxine. The difference in behavior was attributed to the lesser degree of ionization of the phenolic hydroxyl group of triiodothyronine, which at $\mathrm{pH} 7.4$ is only one-tenth as highly ionized as that of thyroxine. At $\mathrm{pH}$ 8.6, with greater ionization to the phenolate form, tri-

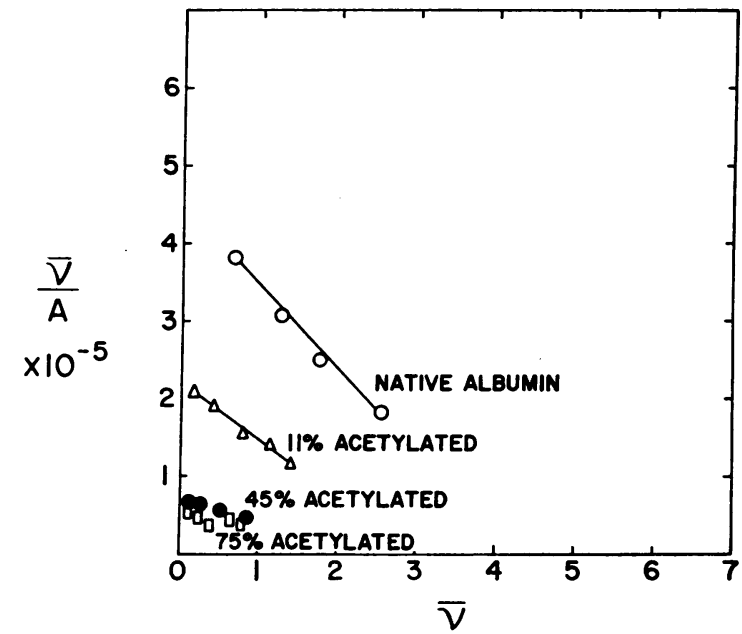

Fig. 7. The BINDing of thyroxine By ACETylated HUMAN SERUM Albumin PREPARATIONS. $30^{\circ} \mathrm{C}$, pH 8.6, $0.05 \mathrm{M}$ Tris- $0.1 \cdot \mathrm{M} \mathrm{NaCl}$.

iodothyronine was found to be more firmly bound by albumin. While other factors besides electrostatic attraction may be involved in binding, the data indicate an important role for the interaction of free cationic groups on the protein molecule and the anionic phenolate groups of thyroxine and triiodothyronine. The interaction suggested in Figure 8 may be regarded as a tentative and simplified hypothesis, consistent with the data at hand but not definitely proven. An alternative explanation may be advanced for the observations of reduced binding at strongly alkaline reaction $(\mathrm{pH}$ 10.9 and 11.2), as well as for the behavior of the acetylated proteins. In both circumstances the protein molecule should have a greater net negative charge because of the loss of free cationic

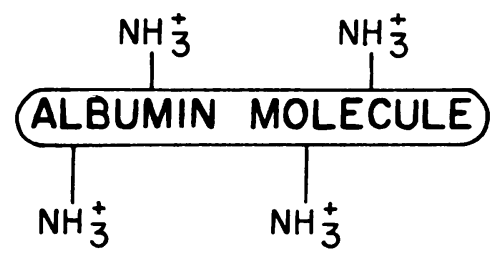<smiles>C=C([Al])C([O-])=C(C)C</smiles>

$\mathrm{pH} 7.4$

PHENOLIC HYDROXYL GROUP $82 \%$ IONIZED

\section{THYROXINE}

Fig. 8. SChematic RePRESENTATION OF HyPothesis of THYROXINE-ALBUMIN INTERACTION. 
$\left(-\mathrm{NH}_{3}{ }^{+}\right)$groups, whether by acetylation or by loss of a proton. Thus, the reduction of affinity between a more negatively charged protein molecule and the thyroxine anion does not require the specific hypothesis suggested in Figure 8. Moreover, configurational changes or other possible alterations have not been assessed. Further studies with modified proteins and with thyroxine analogs may provide more evidence concerning the nature of the interaction.

\section{DISCUSSION}

The theoretical treatment of the interaction of small molecules with proteins has been considered extensively by Scatchard (2-4), Klotz (5), and many other workers. Scatchard has simplified the theoretical consideration of the problem by discussing it under the four questions listed below; the answers for the thyroxine-albumin interaction are provided by the present data.

1. "How many?" (How many small molecules are bound by each protein molecule?) At physiological $\mathrm{pH}$, in isotonic phosphate or Tris- $\mathrm{NaCl}$ buffer, $n=4$, signifying that the human serum albumin molecule may bind four thyroxine molecules at its primary binding sites.

2. "How tightly?" (How tightly are the small molecules bound to the protein?) The apparent association constant of approximately 100,000 is of an order of magnitude comparable with the binding of many drugs and dyes. Albumin binds thyroxine somewhat more tightly than it binds the anionic dye, methyl orange (5), or tryptophan (6), but much less tightly than it binds the free fatty acids of serum (12). In contrast, triiodothyronine is bound only one-tenth as tightly as thyroxine at $\mathrm{pH} 7.4$, a difference attributed to the greater degree of dissociation of the phenolic hydroxyl group of thyroxine.

3. "Where?" (At what sites on the protein molecule does binding occur?) Since the negatively charged phenolic hydroxyl group appears to be one site of attachment of the iodothyronine molecule, it seems reasonable to suppose that free cationic groups on the protein are binding sites. The reduction of binding at strongly alkaline reaction ( $\mathrm{pH} 10.9$ and 11.2) is compatible with such a hypothesis. Experimental support is afforded by the studies in which diminished binding was observed after lysyl $\epsilon$-amino groups of the protein had been blocked by acetylation. The evidence is not, however, a conclusive demonstration that $-\mathrm{NH}_{3}{ }^{+}$groups are the specific binding sites. In strongly alkaline solutions where $-\mathrm{NH}_{3}{ }^{+}$groups lose protons, or with these groups blocked, the protein molecule would have a greater net negative charge that could reduce its affinity for the thyroxine anion.

4. "Why?" (What is the biological significance of binding, if any?) In normal serum, the albumin molecules are present in vast excess. The ratio approximates 10,000 albumin molecules to one of thyroxine. Under these circumstances an even smaller minority than $1 / 10,000$ of the albumin molecules would carry a bound thyroxine molecule, since most of the serum thyroxine is bound by the thyroxine-binding $\alpha$-globulin and prealbumin fractions. Therefore, the tightness of albumin binding is not a limiting factor. Nevertheless, it has biological relevance as a secondary carrier.

From the binding constants established for human serum albumin it is possible to estimate the free thyroxine concentration of serum by employing the observation that approximately 15 per cent of serum thyroxine is albumin-bound upon electrophoresis. With the addition of tracer amounts of thyroxine, the mean value of 15 per cent has been obtained both by Ingbar and Freinkel (7) and Robbins and Rall (26) with respective buffer systems of $\mathrm{pH} 8.6$ and 8.4 ; the precise value at $\mathrm{pH} 7.4$ has not thus far been determined in a system that separates the prealbumin carrier. However, the use of 15 per cent seems reasonable as a first-order approximation, in view of the similarity of albumin binding of thyroxine at $\mathrm{pH} 7.4$ and $\mathrm{pH}$ 8.6. The 85 per cent bound by the other carriers was ignored for the present calculation.

The equation most conveniently applied is that of Scatchard- $\bar{\nu}=n k \mathrm{~A} /(1+k \mathrm{~A})$-which represents the form from which the equation $\bar{\nu} / \mathrm{A}=$ $k n-k \bar{\nu}$ is derived algebraically. If an average normal butanol-extractable iodine of $5.1 \mu \mathrm{g}$ per $100 \mathrm{ml}$ is assumed, this would correspond to a serum thyroxine concentration of $7.78 \mu \mathrm{g}$ per 100 $\mathrm{ml}$, or $1 \times 10^{-7} \mathrm{M}$. Since approximately $15 \mathrm{per}$ cent of the total serum thyroxine is albumin- 
bound, the value for the thyroxine-albumin complex would be $1.5 \times 10^{-8} \mathrm{M}$. The mean normal concentration of albumin of $4.5 \mathrm{~g}$ per $100 \mathrm{ml}$ corresponds to a concentration of $6.5 \times 10^{-4} \mathrm{M}$. Therefore $\bar{\nu}=\left(1.5 \times 10^{-8} \mathrm{M}\right) /\left(6.5 \times 10^{-4} \mathrm{M}\right)=$ $2.3 \times 10^{-5}$. Since the equilibrium dialysis studies reported have given values of 4 for $n$, and 100,000 for $k$, we may substitute in the equation and solve for $A$, the free thyroxine concentration of serum. The value of $0.6 \times 10^{-10} \mathrm{M}$ obtained corresponds to the predictions of Robbins and Rall $(8,9)$. A value of $1.3 \times 10^{-10} \mathrm{M}$ has been obtained in this laboratory by dialysis of whole serum, as reported separately (21). The discrepancy may be attributed to the extrapolation of binding data to undiluted serum with its many small molecules (27), the partial removal of fatty acids bound to albumin, and the use of data from electrophoresis at $\mathrm{pH}$ 8.6.

\section{SUMMARY}

1. Equilibrium dialysis has been employed to investigate the binding of thyroxine by human serum albumin. Various temperatures and buffers were used, including $38^{\circ} \mathrm{C}, \mathrm{pH} 7.4$, and 0.15 ionic strength (isotonic).

2. Detailed studies of various albumin preparations yielded results consistent with four primary binding sites per molecule, with an apparent association constant of approximately 100,000.

3 . Studies exploring variation in $\mathrm{pH}$ and behavior of acetylated albumin preparations suggested that four cationic groups on the protein molecule interact with the anionic phenolate groups of thyroxine and its analogs. The evidence is compatible with the hypothesis that the four primary binding sites are $\epsilon$-amino groups of lysine residues of albumin, but the nature of the binding sites is not considered proven.

4. With the observation that 15 per cent of the total serum thyroxine is bound to albumin, it was possible to employ the binding constants obtained to compute the theoretical free thyroxine concentration of serum; the value calculated was $0.6 \times$ $10^{-10} \mathrm{M}$.

\section{ACNOWLEDGMENTS}

The authors wish to express gratitude to Robert Danziger, Alexander Hegedus and Thornton S. Walker for valuable technical assistance.

\section{REFERENCES}

1. Sterling, K., and Tabachnick, M. Determination of the binding constants for the interaction of thyroxine and its analogues with human serum albumin. J. biol. Chem. 1961, 236, 2241.

2. Scatchard, G. The attractions of proteins for small molecules and ions. Ann. N. Y. Acad. Sci. 1949, $51,660$.

3. Scatchard, G., Hughes, W. L., Jr., Gurd, F. R. N., and Wilcox, P. E. The interaction of proteins with small molecules and ions in Chemical Specificity in Biological Interactions, F. R. N. Gurd, Ed. New York, Academic Press, 1954, p. 193.

4. Scatchard, G., Coleman, J. S., and Shen, A. L. Physical chemistry of protein solutions. VII. The binding of some small anions to serum albumin. J. Amer. chem. Soc. 1957, 79, 12.

5. Klotz, I. M. Protein interactions in The Proteins; Chemistry, Biological Activity, and Methods, $\mathrm{H}$. Neurath and K. Bailey, Eds. New York, Academic Press, 1953, vol. 1, part B, p. 727.

6. McMenamy, R. H., and Oncley, J. L. The specific binding of L-tryptophan to serum albumin. J. biol. Chem. 1958, 233, 1436.

7. Ingbar, S. H., and Freinkel, N. Regulation of the peripheral metabolism of the thyroid hormones. Recent Progr. Hormone Res. 1960, 10, 353.

8. Robbins, J., and Rall, J. E. The interaction of thyroid hormones and protein in biological fluids. Recent Progr. Hormone Res. 1957, 13, 161.

9. Robbins, J., and Rall, J. E. Proteins associated with the thyroid hormones. Physiol. Rev. 1960, 40, 415.

10. Sterling, K., and Tabachnick, M. Paper electrophoretic demonstration of thyroxine-binding prealbumin fraction in serum. Endocrinology 1961, 68, 1073.

11. Dintzis, H. M. Studies on the Dielectric Properties of Human Serum Mercaptalbumin Solutions. Thesis, Harvard University, 1952.

12. Goodman, D. S. The interaction of human serum albumin with long-chain fatty acid anions. J. Amer. chem. Soc. 1958, 80, 3892.

13. Goodman, D. S. Preparation of human serum albu$\min$ free of long-chain fatty acids. Science 1957, $125,1296$.

14. Fraenkel-Conrat, H., Bean, R. S., and Lineweaver, H. Essential groups for the interaction of ovomucoid (egg white trypsin inhibitor) and trypsin, and for tryptic activity. J. biol. Chem. 1949, 177, 385.

15. Tabachnick, M., and Sobotka, H. Azoproteins. II. A spectrophotometric study of the coupling of diazotized arsanilic acid with proteins. J. biol. Chem. 1960, 235, 1051.

16. Gornall, A. G., Bardawill, C. J., and David, M. M. Determination of serum proteins by means of the biuret reaction. J. biol. Chem. 1949, 177, 751.

17. Cohn, E. J., Hughes, W. L., Jr., and Weare, J. H. Preparation and properties of serum and plasma 
proteins. XIII. Crystallization of serum albumins from ethanol-water mixtures. J. Amer. chem. Soc. 1947, 69, 1753.

18. Albright, E. C., and Larson, F. C. Metabolism of L-thyroxine by human tissue slices. J. clin. Invest. 1959, 38, 1899.

19. Gemmill, C. L., and Plunkett, R. L. The kinetics of the inhibition by thyroxine of the cupric chloride catalyzed oxidation of ascorbic acid. Arch. Biochem. 1952, 36, 434.

20. Lardy, H. Effect of thyroid hormones on enzyme systems in The Thyroid, A. Edelmann, H. J. Curtis and M. E. Koshland, Eds. Upton, N. Y., Brookhaven Nat. Lab., 1954, p. 90.

21. Sterling, K., and Hegedus, A. Measurement of free thyroxine concentration in human serum. J. clin. Invest. 1962, 41, 1031.
22. Teresi, J. D., and Luck, J. M. The combination of organic anions with serum albumin. VIII. Fatty acid salts. J. biol. Chem. 1952, 194, 823.

23. Lein, A. Thyroxine binding by bovine serum albumin. Fed. Proc. 1952, 11, 91.

24. Lein, A. The binding of thyroxine, diiodotyrosine, and triiodothyronine by bovine serum proteins. Abstracts of Papers of 123rd Meeting of Amer. Chem. Soc., Div. of Biol. Chem., Section 42, March, 1953, p. 16C.

25. Klotz, I. M., and Walker, F. M. The binding of organic ions by proteins. Charge and $\mathrm{pH}$ effects. J. Amer. chem. Soc. 1947, 69, 1609.

26. Rall, J. E. Personal communication.

27. McMenamy, R. H., Lund, C. C., Van Marcke, J., and Oncley, J. L. The binding of L-tryptophan in human plasma at $37^{\circ}$ C. Arch. Biochem. 1961, 93, 135. 